\title{
Effect of Collimator Thickness on Build-Up Factor Value for $\gamma$-Radiation Using Inferential Statistic
}

\author{
1. Panji Prawita Aji*, ${ }^{1}$ Giner Maslebu, ${ }^{1}$.Suryasatriya Trihandaru \\ ${ }^{1}$,Department of Physics, Satya Wacana Christian University, Salatiga, 50711 Indonesia \\ *Corresponding author email: panjiaji19@gmail.com
}

\begin{abstract}
A study of the effect of collimator thickness on the Build-Up factor value for the $\gamma$-radiation source has been conducted. The $\gamma$-radiation source used is from Cesium-137. The materials used in this research are concrete and wood, each of which was divided into $6 \mathrm{~cm}$ and $9 \mathrm{~cm}$ thickness. Data retrieval is done using Vernier Interface with Logger Pro 1.8 application. The data obtained are 600 radiation counts for each material thickness. The data processing of the enumeration results using inferential statistics is done to analyze the thickness of the collimator to the Build-up factor value. The effect of the thickness of some of these materials is important to determine the value of Build-up factor.The result obtained from the calculation is the Build-up factor value increases along with the increasing thickness of the collimator for all materials. It is obtained that the Build-up factor value is influenced by the thickness of the collimator. The $B$ value for $6 \mathrm{~cm} \& 9 \mathrm{~cm}$ wood collimator respectively was $12,3 \%$ and $59,83 \%$ while for $6 \mathrm{~cm}$ and $9 \mathrm{~cm}$ concrete collimator respectively was $36,88 \%$ and $72,95 \%$ from $B$ reference. The study of the Build-up factor will be very useful in its application to the manufacture of radiation shields.
\end{abstract}

Keywords: Build-up factor, Cesium-137, Collimator Thickness, $\gamma$-Radiation, Inferential Statistic

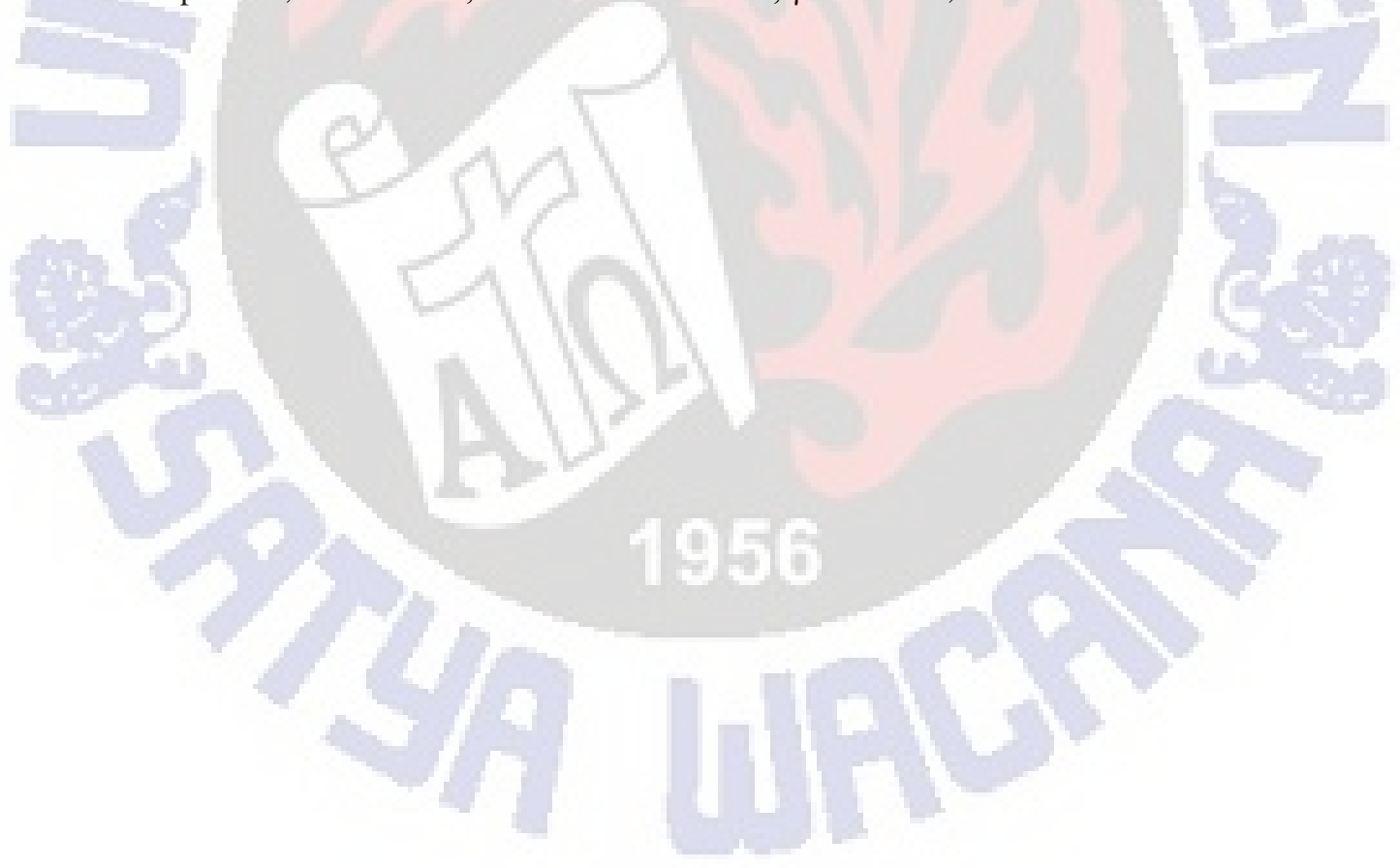

